\title{
Nutritional regulation of long-chain PUFA biosynthetic genes in rainbow trout (Oncorhynchus mykiss)
}

\author{
Melissa K. Gregory ${ }^{1 *}$, Robert O. Collins ${ }^{2}$, Douglas R. Tocher ${ }^{3}$, Michael J. James ${ }^{1}$ \\ and Giovanni M. Turchini ${ }^{2}$ \\ ${ }^{1}$ Rheumatology Unit, Royal Adelaide Hospital, Adelaide, SA 5000, Australia \\ ${ }^{2}$ School of Life and Environmental Sciences, Deakin University, Warmambool, VIC 3280, Australia \\ ${ }^{3}$ School of Natural Sciences, Institute of Aquaculture, University of Stirling, Stirling FK9 4LA, Scotland, UK \\ (Submitted 19 August 2015 - Final revision received 11 January 2016 - Accepted 15 February 2016 - First published online 18 March 2016)
}

\section{Abstract}

Most studies on dietary vegetable oil in rainbow trout (Oncorbynchus mykiss) have been conducted on a background of dietary EPA $(20: 5 n-3)$ and DHA $(22: 6 n-3)$ contained in the fishmeal used as a protein source in aquaculture feed. If dietary EPA and DHA repress their endogenous synthesis from $\alpha$-linolenic acid (ALA, 18:3n-3), then the potential of ALA-containing vegetable oils to maintain tissue EPA and DHA has been underestimated. We examined the effect of individual dietary $n-3$ PUFA on the expression of the biosynthetic genes required for metabolism of ALA to DHA in rainbow trout. A total of 720 juvenile rainbow trout were allocated to twenty-four experimental tanks and assigned one of eight diets. The effect of dietary ALA, EPA or DHA, in isolation or in combination, on hepatic expression of fatty acyl desaturase (FADS) $2 a(\Delta 6), F A D S 2 b(\Delta 5)$, elongation of very long-chain fatty acid (ELOVL) 5 and ELOVL2 was examined after 3 weeks of dietary intervention. The effect of these diets on liver and muscle phospholipid PUFA composition was also examined. The expression levels of FADS2a(A6), ELOVL5 and ELOVL2 were highest when diets were high in ALA, with no added EPA or DHA. Under these conditions ALA was readily converted to tissue DHA. Dietary DHA had the largest and most consistent effect in down-regulating the gene expression of all four genes. The ELOVL5 expression was the least responsive of the four genes to dietary $n-3$ PUFA changes. These findings should be considered when optimising aquaculture feeds containing vegetable oils and/or fish oil or fishmeal to achieve maximum DHA synthesis.

Key words: Desaturase: DHA: Elongase: $\boldsymbol{n}$-3 Fatty acids: PUFA

The association of fish and fish oil with cardiac health is linked closely to their contents of $n$-3 long-chain (LC) PUFA, especially EPA $(20: 5 n-3)$ and DHA $(22: 6 n-3)^{(1)}$. In wild fish, EPA and DHA are obtained from the diet comprising of aquatic plants and algae or other fish ${ }^{(2)}$. In farmed fish, EPA and DHA have been supplied by inclusion of fishmeal and fish oil in feeds. Because of the finite supply of fish oil that limits availability and drives up the price, vegetable oils containing $n$-3 PUFA have been used increasingly to replace fish oil in aquaculture feeds. However, the $n$ - 3 PUFA content of vegetable oils is due to the shorter-chain $\alpha$-linolenic acid (ALA, 18:3n-3), and therefore an important commercial issue is the ability of aquaculture species to metabolise ALA to EPA and, in particular, to DHA.

In vertebrates the metabolism of ALA to DHA requires three desaturation and three elongation steps that in many species can be performed by fatty acyl desaturase (FADS) enzymes, $\Delta 6$ and $\Delta 5$ desaturase, and elongation of very long-chain fatty acid (ELOVL) enzymes, ELOVL5 and ELOVL2. The metabolism of
ALA to $n$-3 LC-PUFA has been studied in several fish species, including rainbow trout (Oncorbynchus mykiss). However, most studies of ALA desaturation and elongation have been conducted on a background of dietary EPA and DHA, which is an inevitable consequence of using fishmeal as a protein source in aquaculture feed ${ }^{(3-6)}$. There was increased conversion of ${ }^{14} \mathrm{C}$-labelled ALA and EPA to ${ }^{14} \mathrm{C}$-DHA in hepatocytes isolated from rainbow trout fed vegetable oil compared with those fed fish oil ${ }^{(7)}$. This suggested that dietary EPA and DHA may be repressing the expression of at least some of the DHA biosynthetic genes, and therefore studies that include dietary EPA and DHA may not allow measurement of the full potential of dietary ALA to act as a source of endogenously produced EPA and DHA.

The recent identification and functional characterisation of ELOVL2 ${ }^{(8)}$ and $\Delta 5$ desaturase $^{(9)}$ in rainbow trout, together with the previously characterised ELOVL $5^{(10)}$ and $\Delta 6$ desaturase ${ }^{(11)}$, means that the fatty acid substrate specificities of the four

Abbreviations: ALA, $\alpha$-linolenic acid; DPA, docosapentaenoic acid; ELOVL, elongation of very long-chain fatty acid; FADS, fatty acyl desaturase; LC-PUFA, longchain PUFA.

* Corresponding author: M. K. Gregory, fax +61 88222 5895, email melissa.gregory@health.sa.gov.au 
enzymes required for ALA to DHA conversion are well characterised. However, the regulation of these genes in response to dietary $n-3$ fatty acids has not been fully characterised. We examined the effect of dietary ALA, EPA or DHA, in isolation and in combination, on the regulation of expression levels of the four LC-PUFA biosynthetic

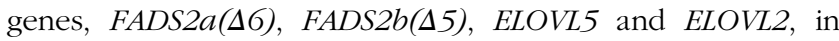
rainbow trout.

\section{Methods}

\section{Animals and housing}

A total of 800 mixed-sex diploid rainbow trout fingerlings (approximately $2.5 \mathrm{~g}$ ) were sourced from the Victorian Department of Primary Industries Hatchery, transferred to Deakin University's Aquaculture Research Facility, and acclimatised to the new environmental conditions in two 1000

litre tanks for 2 weeks. The fish were fed a commercial diet
(Nova SS, $2 \mathrm{~mm}$; Skretting) for $3 \mathrm{~d}$ before being fed a low $n-3$ PUFA reference diet for 2 weeks to reduce baseline tissue EPA and DHA contents. The experiment was conducted in a thermostatically controlled, closed-loop recirculating freshwater aquaculture system, with physical and biological filtration and UV sterilisation. The system was maintained within optimum temperature and water-quality levels, with a $12 \mathrm{~h}$ light- $12 \mathrm{~h}$ dark cycle at $13^{\circ} \mathrm{C} \pm 1^{\circ} \mathrm{C}$. All procedures involving fish handling and experimentation conformed to the Australian Code of Practice for the Care and Use of Animals for Scientific Purposes and were approved by the Deakin University Animal Ethics Committee (project ID G37-2014).

\section{Diets and experimental design}

Eight iso-proteic and iso-lipidic experimental diets were formulated and manufactured to contain $42 \%$ protein and $20 \%$ lipid. The added dietary oil source was the only variable (Table 1). The oil sources were added at $174 \mathrm{~g} / \mathrm{kg}$ and included linseed oil

Table 1. Formulation and proximate composition ( $\mathrm{g} / \mathrm{kg}$ dry weight) of the experimental diets

\begin{tabular}{|c|c|c|c|c|c|c|c|c|}
\hline & \multicolumn{8}{|c|}{ Experimental diet } \\
\hline & Low $n-3$ PUFA & ALA & EPA & DHA & $A L A+E P A$ & $\mathrm{ALA}+\mathrm{DHA}$ & $\mathrm{ALA}+\mathrm{EPA}+\mathrm{DHA}$ & $\mathrm{EPA}+\mathrm{DHA}$ \\
\hline \multicolumn{9}{|l|}{ Dietary ingredients (g/kg) } \\
\hline Pregel starch* & $197 \cdot 3$ & $197 \cdot 3$ & $197 \cdot 3$ & $197 \cdot 3$ & $197 \cdot 3$ & $197 \cdot 3$ & $197 \cdot 3$ & $197 \cdot 3$ \\
\hline Poultry meal ${ }^{*}$ & $116 \cdot 1$ & $116 \cdot 1$ & $116 \cdot 1$ & $116 \cdot 1$ & $116 \cdot 1$ & $116 \cdot 1$ & $116 \cdot 1$ & $116 \cdot 1$ \\
\hline Wheat glutent & $81 \cdot 3$ & $81 \cdot 3$ & $81 \cdot 3$ & $81 \cdot 3$ & $81 \cdot 3$ & $81 \cdot 3$ & $81 \cdot 3$ & $81 \cdot 3$ \\
\hline Fishmeal $^{*}$ & 58.0 & $58 \cdot 0$ & $58 \cdot 0$ & $58 \cdot 0$ & $58 \cdot 0$ & 58.0 & 58.0 & $58 \cdot 0$ \\
\hline Blood meal $^{*}$ & 58.0 & $58 \cdot 0$ & $58 \cdot 0$ & $58 \cdot 0$ & $58 \cdot 0$ & $58 \cdot 0$ & $58 \cdot 0$ & $58 \cdot 0$ \\
\hline Meat and bone meal $\ddagger$ & $58 \cdot 0$ & $58 \cdot 0$ & $58 \cdot 0$ & $58 \cdot 0$ & $58 \cdot 0$ & $58 \cdot 0$ & 58.0 & $58 \cdot 0$ \\
\hline Soyabean meal ${ }^{*}$ & $58 \cdot 0$ & $58 \cdot 0$ & $58 \cdot 0$ & $58 \cdot 0$ & $58 \cdot 0$ & 58.0 & 58.0 & $58 \cdot 0$ \\
\hline Soyaisolate§ & $58 \cdot 0$ & $58 \cdot 0$ & $58 \cdot 0$ & 58.0 & $58 \cdot 0$ & 58.0 & $58 \cdot 0$ & 58.0 \\
\hline Rice protein isolate§ & $58 \cdot 0$ & $58 \cdot 0$ & $58 \cdot 0$ & $58 \cdot 0$ & $58 \cdot 0$ & $58 \cdot 0$ & 58.0 & $58 \cdot 0$ \\
\hline Pea protein isolate§ & 58.0 & $58 \cdot 0$ & $58 \cdot 0$ & $58 \cdot 0$ & $58 \cdot 0$ & $58 \cdot 0$ & $58 \cdot 0$ & $58 \cdot 0$ \\
\hline Vitamin and mineral mix\| & $7 \cdot 0$ & $7 \cdot 0$ & $7 \cdot 0$ & $7 \cdot 0$ & $7 \cdot 0$ & $7 \cdot 0$ & $7 \cdot 0$ & $7 \cdot 0$ \\
\hline Celiteף & $5 \cdot 0$ & $5 \cdot 0$ & $5 \cdot 0$ & $5 \cdot 0$ & $5 \cdot 0$ & $5 \cdot 0$ & $5 \cdot 0$ & $5 \cdot 0$ \\
\hline Choline* $^{*}$ & $5 \cdot 0$ & $5 \cdot 0$ & 5.0 & $5 \cdot 0$ & $5 \cdot 0$ & $5 \cdot 0$ & $5 \cdot 0$ & $5 \cdot 0$ \\
\hline Monosodium phosphate* & $4 \cdot 0$ & $4 \cdot 0$ & 4.0 & $4 \cdot 0$ & $4 \cdot 0$ & $4 \cdot 0$ & $4 \cdot 0$ & $4 \cdot 0$ \\
\hline Lysine* & 1.5 & 1.5 & 1.5 & 1.5 & 1.5 & 1.5 & 1.5 & 1.5 \\
\hline Methionine* & 1.0 & $1 \cdot 0$ & 1.0 & $1 \cdot 0$ & $1 \cdot 0$ & 1.0 & $1 \cdot 0$ & $1 \cdot 0$ \\
\hline Taurine* & 1.0 & 1.0 & 1.0 & 1.0 & 1.0 & 1.0 & 1.0 & 1.0 \\
\hline Vitamin $\mathrm{C}^{*}$ & 0.5 & 0.5 & 0.5 & 0.5 & 0.5 & 0.5 & 0.5 & 0.5 \\
\hline ARASCO oil** & $12 \cdot 3$ & $12 \cdot 9$ & 0.0 & $4 \cdot 1$ & $7 \cdot 4$ & $8 \cdot 1$ & $5 \cdot 8$ & $2 \cdot 7$ \\
\hline Sunflower oil†† & 39.2 & 0.0 & $34 \cdot 8$ & 32.9 & $19 \cdot 2$ & $17 \cdot 8$ & $24 \cdot 7$ & $34 \cdot 3$ \\
\hline Hydrogenated soyabean oil $\ddagger \ddagger$ & $122 \cdot 6$ & 0.0 & 0.0 & 0.0 & 0.0 & 0.0 & 0.0 & 0.0 \\
\hline Linseed oil§§ & 0.0 & $161 \cdot 2$ & 0.0 & 0.0 & $73 \cdot 8$ & $74 \cdot 1$ & $47 \cdot 9$ & 0.0 \\
\hline Incromega EPA 500TG oil|||| & 0.0 & 0.0 & $139 \cdot 3$ & 0.0 & $73 \cdot 8$ & 0.0 & $47 \cdot 9$ & 68.5 \\
\hline Incromega DHA 500TG oill||| & 0.0 & 0.0 & 0.0 & $137 \cdot 1$ & 0.0 & $74 \cdot 1$ & 47.9 & 68.5 \\
\hline \multicolumn{9}{|l|}{ Proximate composition $(\mathrm{g} / \mathrm{kg})$} \\
\hline Protein & $436 \cdot 1$ & $426 \cdot 9$ & $421 \cdot 7$ & $423 \cdot 2$ & $427 \cdot 5$ & 427.9 & $412 \cdot 9$ & $421 \cdot 1$ \\
\hline Lipid & 224.6 & $206 \cdot 9$ & 191.5 & 208.6 & 210.5 & $212 \cdot 1$ & 204.9 & 208.2 \\
\hline Moisture & 83.3 & 67.7 & $86 \cdot 3$ & 84.9 & $84 \cdot 1$ & $72 \cdot 3$ & 88.1 & 77.8 \\
\hline Ash & 61.4 & $66 \cdot 3$ & $62 \cdot 0$ & 63.6 & 64.2 & $63 \cdot 4$ & 63.0 & 63.7 \\
\hline
\end{tabular}

ALA $a$-linolenic acid (18:3n-3); EPA (20:5n-3); DHA (22:6n-3).

* Ridley Agriproducts.

$\dagger$ Agri Food Ingredients.

‡ The Midfield Group.

§ Bulk Nutrients Grove.

II DSM Nutritional Products.

II Merck KGaA.

** DSM Nutritional Products.

†† Nuseed Global.

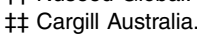

$\S \S$ Melrose Laboratories.

IIII Croda International Plc. 
Table 2. Primers used for quantitative RT-PCR amplification of fatty acyl desaturase ( $F A D S) 2 a(\triangle 6), F A D S 2 b(\triangle 5)$, elongation of very long-chain fatty acid $(E L O V L) 5, E L O V L 2, \beta-A C T I N$ and elongation factor $1 a(E F 1 a)$, including the GenBank accession number of the sequence used for primer design

\begin{tabular}{|c|c|c|c|c|}
\hline Gene & Accession number & Primer & Sequence $5^{\prime} \rightarrow 3^{\prime}$ & Amplicon size \\
\hline$F A D S 2 a(\Delta 6)$ & NM_001124287 & $\begin{array}{l}F \\
R\end{array}$ & $\begin{array}{l}\text { TAGTTTCCCCAGACGTTTGTGTC } \\
\text { CCAAAAAATGATTAAAACAATTACG }\end{array}$ & 69 \\
\hline$F A D S 2 b(\Delta 5)$ & JQ087459 & $\begin{array}{l}\mathrm{F} \\
\mathrm{R}\end{array}$ & $\begin{array}{l}\text { GGACATTTCCTGGATGTTTTTTGAT } \\
\text { TCTGACAAGGATTAAAACAATTATA }\end{array}$ & 78 \\
\hline ELOVL5 & AY605100 & $\begin{array}{l}\mathrm{F} \\
\mathrm{R}\end{array}$ & $\begin{array}{l}\text { CTATGGGCTCTCTGCTGTCC } \\
\text { TATCGTCTGGGACATGGTCA }\end{array}$ & $106^{*}$ \\
\hline ELOVL2 & KM244737 & $\begin{array}{l}\mathrm{F} \\
\mathrm{R}\end{array}$ & $\begin{array}{l}\text { GATGCCTGCTCTTCCAGTTC } \\
\text { CATTGGTGGAGACAGTGTGG }\end{array}$ & $141^{*}$ \\
\hline$\beta-A C T I N$ & NM_001124235 & $\begin{array}{l}\mathrm{F} \\
\mathrm{R}\end{array}$ & $\begin{array}{l}\text { TTTGAGACCTTCAACACCCC } \\
\text { GAGCGTAGCCCTCGTAGATG }\end{array}$ & 142 \\
\hline EF1a & NM_001124339 & $\begin{array}{l}\mathrm{F} \\
\mathrm{R}\end{array}$ & $\begin{array}{l}\text { GGATGGAAGGTCGAACGTAA } \\
\text { TTGTAGACATCCTGGAGGGG }\end{array}$ & 128 \\
\hline
\end{tabular}

* Primers previously published ${ }^{(8)}$.

(Melrose Laboratories) as a source of ALA, Incromega EPA 500TG oil (Croda International Plc) as a source of EPA and Incromega DHA 500TG oil (Croda International Plc) as a source of DHA. The low $n$-3 PUFA reference diet contained minimal ALA, EPA and DHA, whereas the other seven diets were formulated to contain high ALA, EPA or DHA in isolation or in combination (ALA + EPA, $\mathrm{ALA}+\mathrm{DHA}, \mathrm{ALA}+\mathrm{EPA}+\mathrm{DHA}$ or EPA+DHA). Sunflower oil (Nuseed Global) and ARASCO (DSM Nutritional Products) were used to balance the linoleic acid $(18: 2 n-6)$ and arachidonic acid (20:4n-6) contents of each of the diets.

The experimental diets were produced using a meat mincer (Model TJ22-B; Brice Australia) fitted with a 3-mm stainless steel extrusion plate. The feed was dried to $2-3 \%$ moisture in a dark, temperature-controlled fan-forced room at $40^{\circ} \mathrm{C}$ for $48 \mathrm{~h}$. It was ground and mechanically sieved through a nest of 2, 1 and $0 \cdot 5-\mathrm{mm}$ screens. The experimental diets used for the duration of the trial were a composite collected from the 2 and 1-mm screens. Diets were stored at approximately $10^{\circ} \mathrm{C}$ until fed.

The trial consisted of 720 rainbow trout that were weighed and allocated to twenty-four experimental tanks (140 litre tanks). The fish had a mean initial weight of $3 \cdot 6$ (SE $0 \cdot 1) \mathrm{g}$ and were stocked at $30 \mathrm{fish} / \mathrm{tank}$. The fish were assigned one of eight experimental diets ( 3 tanks/treatment) and were fed to apparent satiety twice daily, at 08.30 hours and 17.00 hours, for a period of 3 weeks. Total feed intake was recorded at the end of the trial and mortalities were recorded throughout the trial.

\section{Sampling and chemical analysis}

At the end of the 3-week trial, the fish were euthanised using 30-parts per million AQUI-S (AQUI-S New Zealand Ltd). All fish were weighed and 12 fish per tank were randomly sampled for analysis. The whole liver and a portion of muscle were removed from 6 fish/tank for fatty acid analysis, and samples were stored on ice during the sampling of each tank and then at $-20^{\circ} \mathrm{C}$. A portion of liver and muscle were removed from the remaining 6 fish/tank for gene expression analysis. These samples were placed immediately into RNAlater, stored on ice during the sampling of each tank, followed by storage at $4^{\circ} \mathrm{C}$ overnight before being transferred to $-80^{\circ} \mathrm{C}$.
The proximate compositions of experimental diets were determined according to standard procedures ${ }^{(12)}$. Briefly, protein $(\mathrm{N} \times 6.25)$ was measured using an automated Kjeltec 2300 (Foss Tecator), moisture by drying samples in an oven at $105^{\circ} \mathrm{C}$ to a constant weight and ash by incinerating samples in a muffle furnace (Wit; C \& L Tetlow) at $550^{\circ} \mathrm{C}$ for $18 \mathrm{~h}$. Lipid content was determined using chloroform-isopropanol $(2: 1, \mathrm{v} / \mathrm{v})$ extraction basically according to the method of Folch et $a{ }^{(13)}$, and $0.005 \%(\mathrm{w} / \mathrm{v})$ butylated hydroxyanisole was added to reduce lipid oxidation during processing.

Rainbow trout liver fatty acyl desaturase 2a( $(\Delta 6)$, fatty acyl desaturase $2 b(\Delta 5)$, elongation of very long-chain fatty acid 2 and elongation of very long-chain fatty acid 5 gene expression

A Tissuelyser (Qiagen) was used to disrupt and homogenise approximately $15 \mathrm{mg}$ of RNAlater-stabilised liver tissue. Total RNA was extracted with the RNeasy kit (Qiagen) and the quantity and quality of RNA were determined by measuring absorbance at 260 and $280 \mathrm{~nm}$ (NanoDrop Technologies Inc.). Quantitative RT-PCR (qRT-PCR) was performed using an Applied Biosystems QuantStudio 7 Flex Real-Time PCR System with the Superscript III Platinum SYBR Green One-Step qRT-PCR kit (Invitrogen Australia Pty Ltd). Each $10 \mu$ reaction contained 10 ng of complementary DNA (cDNA), $5 \mu \mathrm{l} 2 \times$ SYBR Green reaction mix, $0 \cdot 2 \mu \mathrm{l}$ SuperScript III RT/Platinum Taq Mix and 200 nм of each primer (Table 2). The cycling conditions were as follows: at $50^{\circ} \mathrm{C}$ for $3 \mathrm{~min}$, at $95^{\circ} \mathrm{C}$ for $5 \mathrm{~min}, 40$ cycles of $95^{\circ} \mathrm{C}$ for $15 \mathrm{~s}$ and $60^{\circ} \mathrm{C}$ for $30 \mathrm{~s}$, followed by $40^{\circ} \mathrm{C}$ for $1 \mathrm{~min}$ and a melt curve analysis of $1^{\circ} \mathrm{C}$ increments from 60 to $95^{\circ} \mathrm{C}$. Agarose gel electrophoresis of the products and melt curve analysis were used to ensure that a single specific product of expected size was obtained. Amplifications were carried out with negative controls (no cDNA template control). Gene expression data are expressed as mean values with their standard errors ( $n$ 3) normalised for the geometric mean of the expression levels of two housekeeping genes, $\beta-A C T I N$ and elongation factor $1 \alpha$, in relative units.

\section{Fatty acid analysis}

Total lipid was extracted from feeds and trout tissues using chloroform-isopropanol $(2: 1, \mathrm{v} / \mathrm{v})$ basically according to the 
Table 3. Fatty acid composition (percentage of total fatty acids) of the experimental diets

\begin{tabular}{|c|c|c|c|c|c|c|c|c|}
\hline & \multicolumn{8}{|c|}{ Experimental diet } \\
\hline & Low $n$-3 PUFA & ALA & EPA & DHA & $A L A+E P A$ & $A L A+D H A$ & $A L A+E P A+D H A$ & $\mathrm{EPA}+\mathrm{DHA}$ \\
\hline $18: 3 n-3$ (ALA) & 0.3 & $35 \cdot 7$ & 1.0 & 0.6 & $17 \cdot 4$ & $17 \cdot 7$ & $11 \cdot 8$ & 0.7 \\
\hline $18: 4 n-3$ (SDA) & 0.0 & 0.0 & $7 \cdot 3$ & 0.6 & 4.4 & 0.4 & $3 \cdot 1$ & 4.6 \\
\hline $20: 4 n-3$ & 0.0 & 0.0 & 0.8 & 0.0 & 0.5 & 0.0 & 0.5 & 0.7 \\
\hline $20: 5 n-3$ (EPA) & 0.3 & 0.3 & $29 \cdot 0$ & $5 \cdot 1$ & $18 \cdot 8$ & $2 \cdot 9$ & $14 \cdot 1$ & $20 \cdot 6$ \\
\hline $22: 5 n-3$ (DPA) & 0.1 & 0.1 & $1 \cdot 1$ & 1.5 & 0.7 & 0.9 & 1.0 & 1.5 \\
\hline $22: 6 n-3(\mathrm{DHA})$ & 0.3 & 0.3 & 7.4 & 33.0 & $5 \cdot 2$ & $19 \cdot 1$ & $15 \cdot 8$ & $22 \cdot 7$ \\
\hline Total $n-3 \mathrm{C}_{18}$ PUFA & 0.3 & $35 \cdot 7$ & 8.3 & $1 \cdot 2$ & 21.8 & $18 \cdot 1$ & 14.9 & $5 \cdot 3$ \\
\hline Total $n$-3 LC-PUFA* & 0.7 & 0.7 & 38.3 & 39.6 & $25 \cdot 2$ & $22 \cdot 9$ & 31.4 & $45 \cdot 5$ \\
\hline $18: 2 n-6$ & 14.4 & 18.5 & $18 \cdot 2$ & $15 \cdot 8$ & $16 \cdot 8$ & $16 \cdot 6$ & $16 \cdot 4$ & $15 \cdot 3$ \\
\hline $18: 3 n-6$ & 0.2 & 0.2 & 0.4 & 0.2 & 0.3 & 0.2 & 0.3 & 0.3 \\
\hline $20: 3 n-6$ & 0.2 & 0.2 & 0.2 & 0.2 & 0.2 & 0.2 & 0.2 & 0.3 \\
\hline $20: 4 n-6$ & $2 \cdot 1$ & $2 \cdot \overline{3}$ & 1.5 & $2 \cdot 1$ & $2 \cdot 3$ & $2 \cdot 3$ & $2 \cdot \overline{2}$ & $2 \cdot 1$ \\
\hline Total $n-6$ PUFA & $17 \cdot 0$ & 21.3 & $20 \cdot 8$ & 21.5 & $19 \cdot 9$ & 21.1 & 20.5 & 19.9 \\
\hline $16: 0$ & $12 \cdot 8$ & $9 \cdot 8$ & $8 \cdot 7$ & $7 \cdot 8$ & 7.9 & $8 \cdot 3$ & $7 \cdot 6$ & $6 \cdot 6$ \\
\hline $18: 0$ & 54.8 & $6 \cdot 1$ & 3.7 & $5 \cdot 5$ & $4 \cdot 3$ & 5.4 & 4.5 & 3.8 \\
\hline Total SFA & 69.5 & $17 \cdot 1$ & $13 \cdot 8$ & $15 \cdot 2$ & $13 \cdot 4$ & $15 \cdot 2$ & 13.4 & 11.8 \\
\hline $16: 1 n-7$ & 0.7 & 0.8 & 1.8 & 1.2 & $1 \cdot 1$ & 0.9 & $1 \cdot 1$ & 1.2 \\
\hline $18: 1 n-9$ & 11.0 & 23.1 & $15 \cdot 2$ & $16 \cdot 2$ & 17.0 & $18 \cdot 8$ & $16 \cdot 3$ & $13 \cdot 1$ \\
\hline $18: 1 n-7$ & 0.5 & 1.0 & 0.9 & $1 \cdot 3$ & 0.8 & $1 \cdot 1$ & 1.0 & 1.0 \\
\hline Total MUFA & $12 \cdot 3$ & $25 \cdot 1$ & 18.6 & $22 \cdot 0$ & $19 \cdot 4$ & 22.5 & $19 \cdot 6$ & $17 \cdot 1$ \\
\hline
\end{tabular}

ALA, $a$-linolenic acid (18:3n-3); EPA, $20: 5 n-3$; DHA, $22: 6 n-3$; SDA, stearidonic acid (18:4n-3); DPA, docosapentaenoic acid (22:5n-3); LC-PUFA, long-chain PUFA.

* Total $n-3$ LC-PUFA is the sum of $20: 3 n-3,20: 4 n-3,20: 5 n-3,22: 5 n-3$ and $22: 6 n-3$.

method of Folch et al. ${ }^{(13)}$. Lipid weight was determined after drying the extracted lipid under $\mathrm{N}_{2}$. Phospholipid fatty acids of liver and muscle tissues were separated by TLC using a mobile phase of petroleum ether-acetone $(3: 1, v / v)$. Total lipid from feeds or phospholipid fatty acids from liver and muscle tissue were methylated in $1 \%(\mathrm{v} / \mathrm{v})$ sulphuric acid in methanol for $3 \mathrm{~h}$ at $70^{\circ} \mathrm{C}$ to prepare fatty acid methyl esters that were extracted in heptane and analysed by GC as described previously ${ }^{(14)}$. The identity of each fatty acid peak in the chromatogram was ascertained by comparing its retention time to authentic lipid standards (Nu-Chek Prep). Fatty acid methyl esters were quantified using GC Chemstation software (Agilent Technologies). All solvents contained $0.005 \%(\mathrm{w} / \mathrm{v})$ butylated hydroxyanisole as an antioxidant. The amount of each fatty acid was expressed as a percentage of the total amount of all fatty acids.

\section{Statistical analysis}

The expression of LC-PUFA biosynthetic genes in fish consuming the experimental diets compared with the low $n-3$ PUFA reference diet was analysed by one-way ANOVA with Dunnett's post hoc test. The liver and muscle fatty acid data were analysed by one-way ANOVA with Tukey's post boc test. All analyses were carried out using Graphpad Prism version 5.03 for Windows (Graphpad Software). Statistical significance was set at $P<0.05$.

\section{Results}

\section{Experimental diets}

The low $n$-3 PUFA diet contained minimal ALA, EPA and DHA with the total $n$-3 PUFA being $1.0 \%$ of total fatty acids (Table 3 ).
The high-ALA diet contained $35.7 \%$ ALA, the high-EPA diet contained $29.0 \%$ EPA, and the high-DHA diet contained $33.0 \%$ DHA (Table 3). The experimental diets with a combination of two $n-3$ PUFA (ALA + EPA, ALA+DHA or EPA+DHA) contained equal amounts of both $n-3$ PUFA, which were approximately half of the amount in the high-ALA-, -EPA- or -DHA-only diets (Table 3). Likewise, the ALA + EPA + DHA diet contained equal amounts of ALA, EPA and DHA, which were each one third of the amount in the high-ALA-, -EPA- or -DHAonly diets (Table 3 ). The total $n-6$ PUFA concentrations were $17 \cdot 0-21 \cdot 5 \%$ of total fatty acids across all diets (Table 3 ). The total lipid content was similar across all diets, with an average of $20 \cdot 8 \%$ (Table 1 ).

\section{Growth performance}

The final body weights of rainbow trout were not statistically different between any of the dietary treatments (Table 4). Similarly, no significant differences were observed for weight gain, dry feed intake, feed conversion ratio, specific growth rate and survival between any of the dietary treatments (Table 4).

\section{The effect of dietary n-3 PUFA on liver long-chain PUFA biosynthetic gene expression}

The effect of dietary ALA, EPA or DHA on the regulation of expression levels of the four LC-PUFA biosynthetic genes was compared with the low $n-3$ PUFA diet. Dietary ALA reduced the expression of FADS $2 a(\Delta 6)$ and FADS $2 b(\Delta 5)$, although the reduced level of $F A D S 2 a(\Delta \sigma)$ was not statistically significant (Fig. 1(a) and (b)). Dietary EPA significantly reduced the expression of ELOVL2 only (Fig. 1(d)). Dietary DHA reduced 
Table 4. Growth performance and feed efficiency of rainbow trout fed the experimental diets for 3 weeks (Mean values with their standard errors; $n$ )

\begin{tabular}{|c|c|c|c|c|c|c|c|c|c|c|c|c|c|c|c|c|}
\hline & \multicolumn{16}{|c|}{ Diet } \\
\hline & \multicolumn{2}{|c|}{ Low n-3 PUFA } & \multicolumn{2}{|c|}{ ALA } & \multicolumn{2}{|c|}{ EPA } & \multicolumn{2}{|c|}{$\mathrm{DHA}$} & \multicolumn{2}{|c|}{$\mathrm{ALA}+\mathrm{EPA}$} & \multicolumn{2}{|c|}{$\mathrm{ALA}+\mathrm{DHA}$} & \multicolumn{2}{|c|}{$\mathrm{ALA}+\mathrm{EPA}+\mathrm{DHA}$} & \multicolumn{2}{|c|}{$\mathrm{EPA}+\mathrm{DHA}$} \\
\hline & Mean & SE & Mean & SE & Mean & SE & Mean & SE & Mean & SE & Mean & SE & Mean & SE & Mean & SE \\
\hline IBW (g) & $3 \cdot 4$ & 0.2 & 3.6 & 0.2 & $3 \cdot 6$ & 0.1 & $3 \cdot 6$ & 0.2 & 3.5 & 0.1 & 3.5 & 0.2 & 3.7 & 0.3 & $3 \cdot 8$ & 0.1 \\
\hline FBW (g) & $6 \cdot 2$ & 0.3 & $6 \cdot 5$ & 0.3 & $5 \cdot 7$ & 0.3 & $5 \cdot 9$ & 0.3 & $6 \cdot 3$ & 0.4 & $6 \cdot 4$ & 0.1 & $6 \cdot 1$ & 0.3 & $6 \cdot 4$ & 0.2 \\
\hline$W G(g)$ & $2 \cdot 8$ & 0.2 & $2 \cdot 9$ & $0 \cdot 1$ & $2 \cdot 0$ & 0.2 & $2 \cdot 3$ & 0.1 & $2 \cdot 8$ & 0.3 & 2.9 & 0.2 & $2 \cdot 4$ & 0.1 & $2 \cdot 6$ & 0.1 \\
\hline WG† (\%) & $81 \cdot 0$ & $4 \cdot 0$ & $81 \cdot 3$ & 3.9 & $56 \cdot 1$ & 3.5 & $62 \cdot 8$ & 1.5 & $80 \cdot 0$ & $8 \cdot 2$ & 84.6 & $12 \cdot 4$ & $66 \cdot 5$ & 8.5 & $67 \cdot 4$ & $2 \cdot 2$ \\
\hline Dry feed intake (g/21 d) & 134.9 & 3.5 & $135 \cdot 4$ & $1 \cdot 1$ & $136 \cdot 4$ & $3 \cdot 8$ & $145 \cdot 7$ & $4 \cdot 2$ & $136 \cdot 9$ & $2 \cdot 0$ & $147 \cdot 0$ & 3.6 & $136 \cdot 7$ & 0.2 & $142 \cdot 1$ & 2.5 \\
\hline FCR & 1.7 & 0.1 & 1.6 & 0.1 & 2.4 & 0.2 & $2 \cdot 3$ & 0.1 & 1.9 & 0.3 & $2 \cdot 1$ & 0.6 & $2 \cdot 0$ & 0.1 & $2 \cdot 0$ & 0.1 \\
\hline SGR§ (\% gain/d) & $2 \cdot 8$ & 0.1 & $2 \cdot 8$ & $0 \cdot 1$ & $2 \cdot 1$ & 0.1 & $2 \cdot 3$ & 0.1 & $2 \cdot 8$ & 0.2 & 2.9 & 0.3 & $2 \cdot 4$ & 0.2 & 2.5 & 0.1 \\
\hline Survivalll (\%) & $98 \cdot 9$ & $1 \cdot 1$ & $98 \cdot 9$ & $1 \cdot 1$ & $97 \cdot 8$ & $1 \cdot 1$ & $97 \cdot 8$ & $1 \cdot 1$ & $96 \cdot 7$ & 1.9 & 94.4 & $5 \cdot 6$ & $98 \cdot 9$ & $1 \cdot 1$ & $96 \cdot 7$ & 1.9 \\
\hline
\end{tabular}

ALA, $a$-linolenic acid (18:3n-3); EPA, $20: 5 n-3$; DHA, $22: 6 n-3$; IBW, initial body weight; FBW, final body weight; WG, wet weight gain.

* There were no significant differences between dietary treatments in any parameter.

$\dagger$ WG $(\%)$, percentage weight gain $=100 \times((\mathrm{FBW}-\mathrm{IBW}) / \mathrm{IBW})$

$\ddagger$ FCR, feed conversion ratio $=$ dry feed intake $(\mathrm{g}) / \mathrm{WG}(\mathrm{g})$.

$\S$ SGR $(\%$ gain/d), specific growth rate $=100 \times(\ln \mathrm{FBW}-\mathrm{In} \mathrm{IBW}) / 21 \mathrm{~d}$.

II Survival $(\%)=100 \times$ (number of fish remaining on day 21 /initial number of fish).

(a)

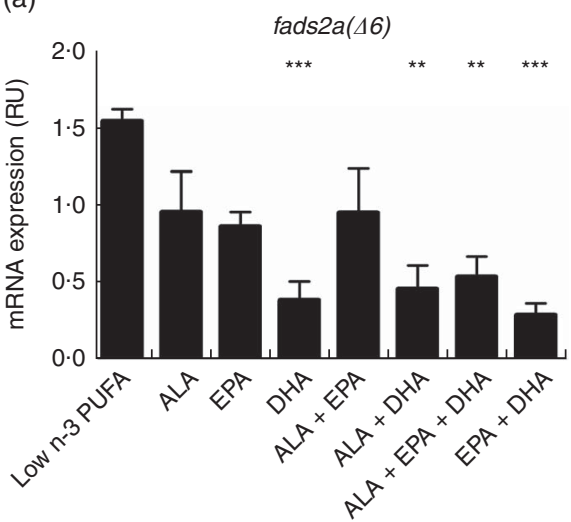

(c)

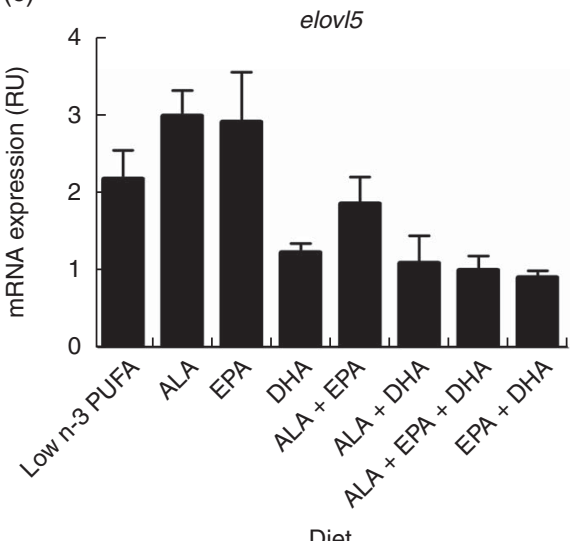

(b)

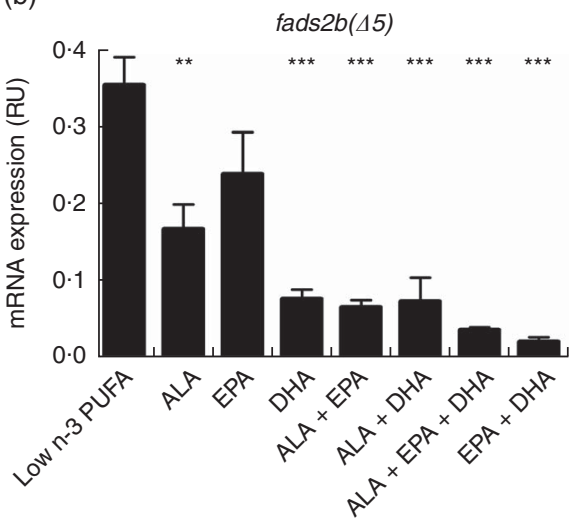

(d)

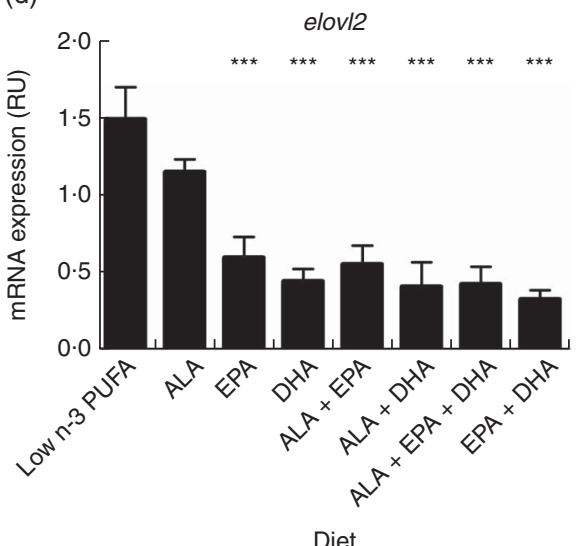

Fig. 1. Rainbow trout liver fatty acyl desaturase $(F A D S) 2 a(\triangle 6)(a), F A D S 2 b(\triangle 5)$ (b), elongation of very long-chain fatty acid (ELOVL)5 (c) and $E L O V L 2$ (d) gene expression after dietary intervention. Values are means $(n 3)$, with standard errors represented by vertical bars normalised for the geometric mean of the expression levels of two housekeeping genes, $\beta-A C T I N$ and elongation factor $1 a(E F 1 a)$, in relative units (RU). The mean value was significantly different from that of the low $n-3$ PUFA diet: ${ }^{* \star} P<0.01,{ }^{* \star *} P<0.001$. ALA, $\alpha$-linolenic acid (18:3n-3); EPA (20:5n-3); DHA (22: $\left.6 n-3\right)$.

the expression of all four genes, with $F A D S 2 a(\Delta 6)$ and $F A D S 2 b$ $(\Delta 5)$ down-regulated by $4 \cdot 2$-fold each, but the reduced ELOVL5 expression did not reach statistical significance (Fig. 1).
The effect of combinations of dietary ALA, EPA or DHA on FADS2a( $\Delta 6)$, FADS $2 b(\Delta 5)$, ELOVL5 and ELOVL2 expression was compared with the effect of the low $n-3$ PUFA diet. Dietary 
Table 5. Lipid content (percentage of wet weight) and fatty acid composition (percentage of total fatty acids) of liver phospholipids after dietary intervention (Mean values with their standard errors; $n 3$ )

\begin{tabular}{|c|c|c|c|c|c|c|c|c|c|c|c|c|c|c|c|c|}
\hline & \multicolumn{16}{|c|}{ Diet } \\
\hline & \multicolumn{2}{|c|}{ Low $n-3$ PUFA } & \multicolumn{2}{|c|}{ ALA } & \multicolumn{2}{|c|}{ EPA } & \multicolumn{2}{|c|}{$\mathrm{DHA}$} & \multicolumn{2}{|c|}{$A L A+E P A$} & \multicolumn{2}{|c|}{$A L A+D H A$} & \multicolumn{2}{|c|}{$\mathrm{ALA}+\mathrm{EPA}+\mathrm{DHA}$} & \multicolumn{2}{|c|}{$\mathrm{EPA}+\mathrm{DHA}$} \\
\hline & Mean & SE & Mean & SE & Mean & SE & Mean & SE & Mean & SE & Mean & SE & Mean & SE & Mean & SE \\
\hline Lipid content & 4.9 & 0.3 & $5 \cdot 1$ & 0.6 & 3.9 & 0.2 & 4.9 & $0 \cdot 2$ & 4.5 & 0.2 & $4 \cdot 0$ & 0.4 & 4.9 & 0.0 & $4 \cdot 0$ & 0.3 \\
\hline \multicolumn{17}{|l|}{ Fatty acids } \\
\hline $18: 3 n-3$ (ALA) & 0.0 & & $2 \cdot 0^{\mathrm{a}}$ & 0.2 & $0.1^{b}$ & 0.0 & 0.0 & & $1 \cdot 3^{\mathrm{a}, \mathrm{c}}$ & 0.4 & $1 \cdot 3^{\mathrm{a}, \mathrm{d}}$ & 0.1 & $0.8^{\mathrm{b}, \mathrm{c}, \mathrm{d}}$ & 0.0 & $0.1^{\mathrm{b}}$ & 0.0 \\
\hline $18: 4 n-3$ (SDA) & 0.0 & & $1 \cdot 1^{a}$ & 0.1 & $0.4^{\mathrm{b}}$ & 0.0 & 0.0 & & $0.3^{\mathrm{b}}$ & 0.0 & $0.3^{\mathrm{b}}$ & 0.0 & $0.2^{\mathrm{b}}$ & 0.0 & 0.0 & \\
\hline $20: 4 n-3$ & 0.0 & & $0.7^{\mathrm{a}}$ & 0.1 & $0.3^{\mathrm{b}, \mathrm{c}}$ & 0.0 & 0.0 & & $0.4^{b}$ & 0.0 & $0 \cdot 2^{\mathrm{c}}$ & 0.0 & $0.3^{\mathrm{b}, \mathrm{c}}$ & 0.0 & $0.2^{c}$ & 0.0 \\
\hline $20: 5 n-3$ (EPA) & $0.2^{\mathrm{a}}$ & 0.0 & $3 \cdot 1^{\mathrm{b}}$ & $0 \cdot 1$ & $8 \cdot 2^{\mathrm{c}}$ & 0.2 & $1 \cdot 3^{\mathrm{d}}$ & $0 \cdot 1$ & $5 \cdot 7^{\mathrm{e}}$ & 0.1 & $1.5^{\mathrm{d}}$ & 0.0 & $3.8^{f}$ & 0.0 & $4 \cdot 4^{\mathrm{g}}$ & 0.1 \\
\hline $22: 5 n-3$ (DPA) & $0 \cdot 3^{\mathrm{a}}$ & 0.0 & $1 \cdot 8^{\mathrm{b}}$ & 0.2 & $1 \cdot 8^{\mathrm{b}}$ & 0.1 & $0.4^{\mathrm{a}, \mathrm{c}}$ & 0.0 & $1.9^{\mathrm{b}}$ & 0.4 & $0.5^{\mathrm{a}, \mathrm{c}}$ & 0.0 & $1 \cdot 1^{a, b}$ & 0.0 & $1 \cdot 2^{\mathrm{b}, \mathrm{c}}$ & 0.0 \\
\hline $22: 6 n-3(\mathrm{DHA})$ & $10 \cdot 8^{\mathrm{a}}$ & $0 \cdot 1$ & $31 \cdot 3^{\mathrm{b}}$ & 0.7 & $40 \cdot 4^{\mathrm{c}}$ & 0.1 & $44 \cdot 9^{d}$ & 1.0 & $36 \cdot 0^{\mathrm{e}}$ & $1 \cdot 7$ & $40 \cdot 8^{\mathrm{C}}$ & 0.8 & $39 \cdot 0^{\mathrm{c}, \mathrm{e}}$ & 0.3 & $42 \cdot 1^{\mathrm{c}, \mathrm{d}}$ & 0.5 \\
\hline Total $n-3 \mathrm{C}_{18}$ PUFA & 0.0 & & $2 \cdot 9^{\mathrm{a}}$ & 0.5 & $0.4^{b, c}$ & 0.2 & 0.0 & & $1.5^{\mathrm{b}}$ & 0.4 & $1 \cdot 7^{\mathrm{a}, \mathrm{b}}$ & 0.3 & $0.9^{\mathrm{b}, \mathrm{c}}$ & 0.1 & $0 \cdot 1^{\mathrm{c}}$ & 0.0 \\
\hline Total $n$-3 LC-PUFA* & $11 \cdot 4^{\mathrm{a}}$ & 0.1 & $37 \cdot 4^{\mathrm{b}}$ & 0.5 & $50.9^{c}$ & 0.3 & $46 \cdot 6^{\mathrm{d}, \mathrm{e}}$ & 1.0 & $44.5^{\mathrm{d}, \mathrm{e}}$ & 1.4 & $43 \cdot 3^{d}$ & 0.8 & $44.5^{\mathrm{d}, \mathrm{e}}$ & 0.3 & $47 \cdot 9^{\mathrm{c}, \mathrm{e}}$ & 0.6 \\
\hline $18: 2 n-6$ & $4 \cdot 8^{\mathrm{a}}$ & 0.1 & $4 \cdot 2^{a, b}$ & 0.3 & $3.8^{\mathrm{b}, \mathrm{c}}$ & 0.2 & $3 \cdot 5^{\mathrm{b}, \mathrm{c}}$ & 0.2 & $3 \cdot 4^{\mathrm{b}, \mathrm{c}}$ & 0.3 & $3 \cdot 5^{\mathrm{b}, \mathrm{c}}$ & 0.0 & $3 \cdot 1^{c}$ & 0.1 & $3 \cdot 2^{\mathrm{C}}$ & 0.1 \\
\hline $18: 3 n-6$ & $0.5^{\mathrm{a}}$ & 0.0 & $0.2^{\mathrm{b}}$ & 0.0 & 0.0 & & 0.0 & & $0 \cdot 1^{\mathrm{b}}$ & 0.0 & $0.1^{\mathrm{b}}$ & 0.0 & $0 \cdot 1^{b}$ & 0.0 & $0.1^{\mathrm{b}}$ & 0.0 \\
\hline $20: 3 n-6$ & $2 \cdot 5^{\mathrm{a}}$ & 0.0 & $1.5^{\mathrm{b}}$ & 0.0 & $0.5^{\mathrm{c}}$ & 0.0 & $0.5^{\mathrm{c}, \mathrm{d}}$ & 0.0 & $0.8^{\mathrm{c}, \mathrm{d}}$ & 0.2 & $0 \cdot 7^{\mathrm{c}, \mathrm{d}}$ & 0.1 & $0.8^{d}$ & 0.0 & $0.5^{\mathrm{c}, \mathrm{d}}$ & 0.0 \\
\hline $20: 4 n-6$ & $10 \cdot 0^{\mathrm{a}}$ & 0.4 & $6 \cdot 3^{\mathrm{b}}$ & 0.2 & $3.8^{c}$ & 0.2 & $3 \cdot 7^{\mathrm{c}, \mathrm{d}}$ & 0.4 & $3 \cdot 3^{\mathrm{c}, \mathrm{d}}$ & 0.2 & $3 \cdot 7^{\mathrm{c}, \mathrm{d}}$ & 0.2 & $3 \cdot 5^{\mathrm{c}, \mathrm{d}}$ & 0.2 & $2 \cdot 5^{\mathrm{d}}$ & 0.2 \\
\hline Total $n-6$ PUFA & $40 \cdot 7^{a}$ & 0.5 & $14 \cdot 6^{\mathrm{b}}$ & 0.6 & $9 \cdot 6^{c}$ & 0.2 & $11 \cdot 6^{\mathrm{c}, \mathrm{d}}$ & 0.7 & $9 \cdot 7^{c}$ & 0.4 & $12 \cdot 0^{d}$ & 0.3 & $8 \cdot 5^{\mathrm{c}, \mathrm{e}}$ & 0.3 & $7 \cdot 2^{\mathrm{e}}$ & 0.3 \\
\hline Total SFA & 28.6 & 0.2 & 29.8 & 0.8 & 28.7 & 0.6 & 29.0 & 0.9 & $30 \cdot 7$ & 1.5 & 29.8 & 0.6 & $32 \cdot 2$ & 0.2 & $32 \cdot 1$ & 0.4 \\
\hline Total MUFA & $19 \cdot 4^{a}$ & 0.5 & $15 \cdot 8^{b}$ & 0.3 & $10 \cdot 9^{c}$ & 0.2 & $12 \cdot 8^{\mathrm{c}, \mathrm{d}}$ & 0.8 & $14 \cdot 1^{b, d}$ & 0.6 & $13 \cdot 6^{b, d}$ & 0.3 & $13 \cdot 9^{b, d}$ & 0.4 & $12 \cdot 8^{\mathrm{c}, \mathrm{d}}$ & 0.5 \\
\hline
\end{tabular}

ALA, a-linolenic acid (18:3n-3); EPA, 20:5n-3; DHA, 22:6n-3; SDA, stearidonic acid (18:4n-3); DPA, docosapentaenoic acid (22:5n-3); LC-PUFA, long-chain PUFA. a,b,c,d,e,f,g Mean values within a row with unlike superscript letters were significantly different $(P<0.05)$ as determined by ANOVA.

* Total $n-3$ LC-PUFA is the sum of $20: 3 n-3,20: 4 n-3,20: 5 n-3,22: 5 n-3$ and $22: 6 n-3$.

$\mathrm{EPA}+\mathrm{DHA}$ significantly reduced the expression of FADS $2 a(\Delta 6), F A D S 2 b(\Delta 5)$ and ELOVL2, although the $13 \cdot 7$-fold down-regulation of $F A D S 2 b(\Delta 5)$ was greater than the $4 \cdot 8$ - and 4.5-fold down-regulation of FADS2a( $\Delta 6)$ and ELOVL2, respectively (Fig. 1). Dietary ALA + EPA + DHA or ALA + DHA also significantly reduced the expression of FADS $2 a(\Delta 6)$, FADS $2 b$ (45) and ELOVL2 (Fig. 1). Dietary ALA, EPA or DHA, in isolation or in combination, did not significantly change the expression of ELOVL5 compared with the low $n$-3 PUFA diet (Fig. 1(c)).

\section{The effect of dietary n-3 PUFA on the liver phospholipid} n-3 PUFA composition

The proportion of stearidonic acid (SDA, 18:4n-3) in the liver increased with dietary ALA (Table 5). The proportion of EPA in the liver increased with dietary ALA and EPA, with the latter resulting in larger increases (Table 5). EPA levels in the liver were significantly higher with dietary ALA alone compared with those with dietary ALA + DHA (Table 5). Liver docosapentaenoic acid (DPA, $22: 5 n-3$ ) increased with dietary ALA or EPA, in isolation or in combination with each other or with DHA, with the exception of dietary ALA + DHA in which DPA levels remained as low as with dietary DHA alone (Table 5). Liver DHA in fish consuming the low $n$-3 PUFA diet was significantly lower than in fish on any other diet. The proportion of DHA in the liver was increased by 3- or 3.7-fold when fish were consuming dietary ALA or EPA, respectively, compared with fish consuming the low $n-3$ PUFA diet (Table 5). Fish consuming dietary DHA had significantly higher liver DHA levels compared with that in fish on any other diet, with the exception of fish consuming dietary EPA + DHA.

\section{The effect of dietary n-3 PUFA on the muscle phospholipid} n-3 PUFA composition

The proportion of SDA in muscle increased with dietary ALA (Table 6). The proportion of EPA in muscle increased with dietary ALA and EPA, with the latter resulting in larger increases, similar to the pattern observed in the liver (Table 6). The percentage of DPA in the muscle increased to a greater extent with dietary EPA alone compared with dietary EPA and DHA (ALA+EPA+DHA and EPA+DHA diets) (Table 6). Muscle DHA in fish consuming the low $n-3$ PUFA diet was significantly lower than that in fish on any other diet (Table 6). In these fish, the proportion of DHA in muscle was $21.7 \%$ of total fatty acids (Table 6), which was higher than the proportion of DHA in the liver, which was $10 \cdot 8 \%$ of total fatty acids (Table 5). The proportion of DHA in muscle was increased by 1.2- or 1.6-fold when fish were consuming dietary ALA or EPA, respectively, compared with the low $n$-3 PUFA diet (Table 6).

\section{Discussion}

This study is unique in that all of the four LC-PUFA biosynthetic genes were examined and the effects of individual $n-3$ PUFA concentrations in the diet were assessed. There have been studies that have directly or indirectly examined the effect of fish oil on some of the elongase and/or desaturase enzymes, and in general these were fish oil-vegetable oil comparisons $^{(4-6,15-17)}$. In addition, the vegetable oil diets containing ALA had a background of EPA and DHA from the inclusion of $7-58 \%$ fishmeal in the dietary formulations, which made examining the effect of ALA on the LC-PUFA biosynthetic genes challenging $^{(4-6,16,17)}$. Dietary fishmeal was reduced to $5 \cdot 8 \%$ in 
Table 6. Lipid content (percentage of wet weight) and fatty acid composition (percentage of total fatty acids) of muscle phospholipids after dietary intervention

(Mean values with their standard errors; $n$ 3)

\begin{tabular}{|c|c|c|c|c|c|c|c|c|c|c|c|c|c|c|c|c|}
\hline & \multicolumn{16}{|c|}{ Diet } \\
\hline & \multicolumn{2}{|c|}{ Low $n$-3 PUFA } & \multicolumn{2}{|c|}{ ALA } & \multicolumn{2}{|c|}{ EPA } & \multicolumn{2}{|c|}{ DHA } & \multicolumn{2}{|c|}{$A L A+E P A$} & \multicolumn{2}{|c|}{$\mathrm{ALA}+\mathrm{DHA}$} & \multicolumn{2}{|c|}{$\mathrm{ALA}+\mathrm{EPA}+\mathrm{DHA}$} & \multicolumn{2}{|c|}{$\mathrm{EPA}+\mathrm{DHA}$} \\
\hline & Mean & SE & Mean & SE & Mean & SE & Mean & SE & Mean & SE & Mean & SE & Mean & SE & Mean & SE \\
\hline Lipid content & $2 \cdot 3$ & 0.2 & $2 \cdot 8$ & 0.1 & $3 \cdot 2$ & 0.3 & $2 \cdot 6$ & 0.4 & $2 \cdot 2$ & $0 \cdot 2$ & 2.5 & 0.2 & $2 \cdot 6$ & 0.2 & 2.5 & 0.2 \\
\hline \multicolumn{17}{|l|}{ Fatty acids } \\
\hline $18: 3 n-3$ (ALA) & $0 \cdot 3^{\mathrm{a}}$ & 0.0 & $7 \cdot 5^{b}$ & 0.2 & $0.3^{\mathrm{a}}$ & 0.0 & $0 \cdot 3^{\mathrm{a}}$ & 0.0 & $3 \cdot 3^{\mathrm{c}}$ & 0.1 & $3 \cdot 1^{\mathrm{c}}$ & 0.0 & $2 \cdot 3^{\mathrm{d}}$ & 0.0 & $0.3^{\mathrm{a}}$ & 0.0 \\
\hline $18: 4 n-3$ (SDA) & $0.2^{\mathrm{a}}$ & 0.0 & $1 \cdot 3^{b}$ & $0 \cdot 1$ & $0.5^{\mathrm{c}}$ & 0.0 & $0.2^{\mathrm{a}}$ & 0.0 & $0.7^{c}$ & 0.0 & $0.4^{d}$ & 0.0 & $0.5^{\mathrm{c}, \mathrm{d}}$ & 0.1 & $0.4^{d}$ & 0.0 \\
\hline $20: 4 n-3$ & $0.3^{\mathrm{a}}$ & 0.0 & $1.0^{\mathrm{b}}$ & 0.0 & $0.6^{c, d}$ & 0.0 & $0 \cdot 3^{\mathrm{a}}$ & 0.0 & $0.7^{c}$ & 0.0 & $0.5^{\mathrm{d}}$ & 0.0 & $0 \cdot 6^{\mathrm{c}, \mathrm{d}}$ & 0.0 & $0.5^{\mathrm{c}, \mathrm{d}}$ & 0.0 \\
\hline $20: 5 n-3$ (EPA) & $3.4^{\mathrm{a}}$ & 0.2 & $4 \cdot 4^{b}$ & 0.2 & $11 \cdot 1^{\mathrm{c}}$ & 0.2 & $4 \cdot 1^{a, b}$ & 0.1 & $8 \cdot 6^{d}$ & 0.3 & $3 \cdot 5^{\mathrm{a}, \mathrm{b}}$ & 0.1 & $7 \cdot 1^{\mathrm{e}}$ & 0.1 & $7 \cdot 7^{\mathrm{d}, \mathrm{e}}$ & 0.4 \\
\hline $22: 5 n-3$ (DPA) & $1 \cdot 1^{\mathrm{a}}$ & 0.0 & $1.6^{\mathrm{b}}$ & 0.0 & $2 \cdot 6^{\mathrm{c}}$ & 0.0 & $1 \cdot 4^{\mathrm{b}, \mathrm{e}}$ & 0.0 & $2 \cdot 4^{d}$ & 0.0 & $1 \cdot 3^{\mathrm{e}}$ & 0.0 & $2 \cdot 0^{f}$ & 0.1 & $2 \cdot 0^{f}$ & 0.0 \\
\hline $22: 6 n-3(\mathrm{DHA})$ & $21 \cdot 7^{\mathrm{a}}$ & 0.0 & $26 \cdot 9^{b}$ & 0.8 & $33 \cdot 7^{\mathrm{c}, \mathrm{e}}$ & 0.4 & $40 \cdot 3^{d}$ & 0.9 & $30 \cdot 4^{b, c}$ & 0.8 & $36 \cdot 2^{\mathrm{e}}$ & 0.6 & $33 \cdot 9^{c, e}$ & 1.3 & 35.9 & $0.7^{\mathrm{e}}$ \\
\hline Total $n-3 \mathrm{C}_{18}$ PUFA & $0.5^{\mathrm{a}}$ & 0.0 & $8.7^{\mathrm{b}}$ & 0.2 & $0.9^{\mathrm{a}}$ & 0.0 & $0.4^{\mathrm{a}}$ & 0.0 & $4 \cdot 0^{c}$ & 0.2 & $3 \cdot 3^{\mathrm{d}}$ & 0.2 & $2 \cdot 9^{d}$ & 0.1 & $0.7^{\mathrm{a}}$ & 0.0 \\
\hline Total $n$-3 LC-PUFA* & $26 \cdot 6^{\mathrm{a}}$ & 0.3 & $34 \cdot 4^{\mathrm{b}}$ & 1.0 & $48 \cdot 0^{\mathrm{C}}$ & 0.2 & $46 \cdot 2^{\mathrm{c}, \mathrm{e}}$ & 0.8 & $42 \cdot 3^{\mathrm{d}}$ & 0.6 & $41.8^{\mathrm{d}}$ & 0.5 & $43 \cdot 7^{\mathrm{d}, \mathrm{e}, \mathrm{f}}$ & 1.3 & $46 \cdot 2^{c, f}$ & 0.6 \\
\hline $18: 2 n-6$ & $10 \cdot 2^{a}$ & 0.4 & $7.5^{\mathrm{b}}$ & 0.1 & $5 \cdot 4^{\mathrm{C}}$ & 0.1 & $5 \cdot 4^{c}$ & 0.1 & $5 \cdot 8^{\mathrm{C}}$ & $0 \cdot 1$ & $5 \cdot 8^{\mathrm{C}}$ & 0.1 & $5 \cdot 9^{\mathrm{c}}$ & 0.2 & $5 \cdot 6^{\mathrm{c}}$ & 0.1 \\
\hline $18: 3 n-6$ & $0.7^{\mathrm{a}}$ & 0.0 & $0.3^{\mathrm{b}}$ & 0.0 & $0.2^{\mathrm{b}}$ & 0.0 & $0.2^{\mathrm{b}}$ & 0.0 & $0.2^{\mathrm{b}}$ & 0.0 & $0.2^{b}$ & 0.0 & $0.3^{b}$ & 0.0 & $0.2^{\mathrm{b}}$ & 0.0 \\
\hline $20: 3 n-6$ & $1 \cdot 6^{\mathrm{a}}$ & 0.1 & $1 \cdot 0^{\mathrm{b}}$ & 0.0 & $0 \cdot 6^{\mathrm{c}}$ & 0.0 & $0.6^{c}$ & 0.0 & $0.7^{\mathrm{c}}$ & 0.0 & $0.7^{\mathrm{c}}$ & 0.0 & $0 \cdot 7^{\mathrm{c}}$ & 0.0 & $0 \cdot 6^{\mathrm{c}}$ & 0.0 \\
\hline $20: 4 n-6$ & $6 \cdot 9^{\mathrm{a}}$ & 0.0 & $5 \cdot 2^{\mathrm{b}}$ & 0.2 & $3 \cdot 1^{\mathrm{c}}$ & 0.1 & $3 \cdot 4^{\mathrm{c}, \mathrm{d}}$ & 0.0 & $3 \cdot 7^{\mathrm{d}, \mathrm{e}}$ & 0.0 & $3 \cdot 7^{\mathrm{d}, \mathrm{f}}$ & $0 \cdot 1$ & $3 \cdot 5^{\mathrm{c}, \mathrm{e}, \mathrm{f}}$ & 0.1 & $3 \cdot 1^{\mathrm{c}}$ & 0.1 \\
\hline Total $n-6$ PUFA & $28 \cdot 5^{\mathrm{a}}$ & 0.3 & $16 \cdot 3^{b}$ & 0.2 & $12 \cdot 6^{\mathrm{c}}$ & 0.1 & $13 \cdot 7^{\mathrm{c}, \mathrm{d}}$ & 0.2 & $13 \cdot 6^{c, d}$ & 0.2 & $14 \cdot 4^{\mathrm{d}, \mathrm{e}}$ & 0.4 & $13 \cdot 9^{\mathrm{c}, \mathrm{e}}$ & 0.5 & $13 \cdot 0^{c}$ & 0.1 \\
\hline Total SFA & $26 \cdot 9$ & 0.3 & $27 \cdot 0$ & 0.2 & $27 \cdot 0$ & 0.1 & $27 \cdot 0$ & 0.1 & $27 \cdot 9$ & $0 \cdot 1$ & $27 \cdot 7$ & 0.2 & $26 \cdot 9$ & 0.1 & $27 \cdot 6$ & 0.5 \\
\hline Total MUFA & $17 \cdot 6^{\mathrm{a}}$ & 0.4 & $14 \cdot 1^{\mathrm{b}}$ & 1.0 & $11.8^{\mathrm{b}}$ & 0.2 & $12 \cdot 7^{b}$ & 0.4 & $12 \cdot 5^{\mathrm{b}}$ & 0.4 & $12 \cdot 7^{b}$ & 0.3 & $12 \cdot 8^{\mathrm{b}}$ & 0.8 & $12 \cdot 6^{\mathrm{b}}$ & 0.3 \\
\hline
\end{tabular}

ALA, a-linolenic acid (18:3n-3); EPA, 20:5n-3; DHA, 22:6n-3; SDA, stearidonic acid (18:4n-3); DPA, docosapentaenoic acid (22:5n-3); LC-PUFA, long-chain PUFA. a,b,c,d,e,f Mean values within a row with unlike superscript letters were significantly different $(P<0.05)$ as determined by ANOVA.

* Total $n-3$ LC-PUFA is the sum of $20: 3 n-3,20: 4 n-3,20: 5 n-3,22: 5 n-3$ and $22: 6 n-3$.

the present study, resulting in experimental diets with minimal EPA and DHA, both $0.3 \%$ of total fatty acids.

The present study found that the highest expressions of all four LC-PUFA biosynthetic genes were in fish fed low dietary $n-3$ PUFA. The expressions of FADS $2 a(\Delta 6), F A D S 2 b(\Delta 5)$ and ELOVL2 were variously repressed by the individual $n-3$ PUFA, none of which repressed the expression of ELOVL5. Of the fatty acids tested, dietary DHA had the largest and most consistent effect in down-regulating all four genes, including reduced expression of $E L O V L 5$, although it was not statistically significant. This is a possible explanation for some of the effects of dietary ALA on the liver content of some of the downstream products of its metabolism. For example, the proportion of SDA resulting from dietary ALA was decreased by the addition of DHA to the diet (1.1 v. $0.3 \%$ of total fatty acids). This could be due to the observed DHA repression of FADS2a( $\Delta 6)$, which codes for $\Delta 6$ desaturase, the enzyme responsible for SDA synthesis. Likewise, the proportion of DPA in fish fed dietary ALA was decreased by the addition of DHA to the diet ( $1.8 v .0 .5 \%$ of total fatty acids). This could be due to the observed DHA repression of ELOVL2, and subsequently the ELOVL2 enzyme responsible for DPA synthesis from EPA.

Irrespective of diet, fish fed diets supplemented with $n$-3 PUFA showed higher levels of DHA in the liver compared with fish fed the low $n-3$ PUFA diet. For example, fish fed dietary ALA showed a 3-fold increase in liver DHA compared with fish fed the low $n$-3 PUFA diet, despite dietary DHA being identical $(0.3 \%$ of total fatty acids). Similar changes were seen in muscle DHA. Clearly, these juvenile fish exhibited an active LC-PUFA biosynthetic pathway that had an impact on the phospholipid fatty acid composition of the liver and muscle tissue. It is possible that adult fish may be less responsive but the use of juveniles allowed greater experimental manipulation.

Endogenously synthesised DHA appeared to have a different effect from dietary DHA on FADS2a( $\Delta 6)$ and $F A D S 2 b(\Delta 5)$ gene expression. For example, dietary EPA resulted in $40.4 \%$ DHA in the liver with no change in expression of FADS2a( $\Delta 6)$ or $F A D S 2 b(\Delta 5)$ compared with the low $n-3$ PUFA diet of $10 \cdot 8 \%$ DHA. However, dietary EPA+DHA down-regulated the expression of FADS $2 a(\Delta 6)$ and $F A D S 2 b(\Delta 5)$ by 4.8- and 13.7fold, respectively, but resulted in the same amount of liver DHA $(42.1 \%)$ as that in the dietary EPA group. This is a very important and novel observation that warrants further tailored investigations. Our findings on reduced FADS $2 a(\Delta 6)$ expression in fish fed dietary EPA + DHA are in agreement with a previous report in rainbow trout that found that $F A D S 2 a(\Delta 6)$ expression was $4 \cdot 1$ fold lower in fish fed a fish oil diet compared with a vegetable oil diet devoid of $n-3$ LC-PUFA ${ }^{(15)}$. Similarly, in Atlantic salmon, dietary EPA + DHA significantly down-regulated the expression of $\Delta 5 \mathrm{fad}, \Delta 6 \mathrm{fad}$ and elovl2 compared with a vegetable oil diet low in $n$-3 LC-PUFA; yet dietary EPA alone had no effect ${ }^{(18)}$.

Previously, liver ELOVL5 expression was shown to be unchanged between rainbow trout fed a fish oil diet and those fed increasing dietary ALA (8.2-32.4\% of total fatty acids) ${ }^{(16)}$. We have now found that neither dietary ALA, EPA nor DHA in isolation or in combination has a significant effect on the expression of ELOVL5 compared with a diet low in $n$-3 PUFA. Of particular interest is the differing effect of dietary EPA on significantly down-regulating the expression of ELOVL2, but not ELOVL5. Previous functional characterisation of the ELOVL2 and ELOVL5 enzymes demonstrated that their substrate specificities towards EPA were similar at the concentrations examined, but ELOVL2 could further elongate EPA to DPA and 
then to $24: 5 n-3^{(8)}$. Therefore, the down-regulation of ELOVL2 by dietary EPA may have a downstream effect on the synthesis of DPA and subsequently DHA, which ELOVL5 cannot compensate for because of the lack of activity towards DPA ${ }^{(8)}$.

Atlantic salmon is closely related to rainbow trout and has $\Delta 6$

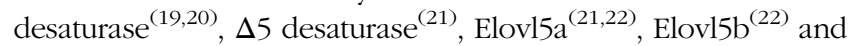
Elovl2 ${ }^{(22)}$ enzymes that have been functionally characterised and shown to be responsible for the metabolism of ALA to DHA. The expression of the Atlantic salmon $\Delta 6 f a d \_a, \Delta 6 f a d \_b, \Delta 6 f a d \_c$, $\Delta 5 \mathrm{fad}$, elovl $5 a$, elovl $5 b$ and elovl2 liver transcripts has been examined in response to dietary fish oil replacement with vegetable oil diets low in $n$ - 3 LC-PUFA and high in $\mathrm{C}_{18}$ PUFA. Collectively these studies showed that $\Delta 6 f a d \_a, \Delta 5 f a d$ and elovl2 expression was up-regulated in vegetable oil-fed Atlantic salmon compared with fish oil-fed salmon ${ }^{(19,20,22-27)}$, as we have seen in rainbow trout. However, in many of these studies the expression of the Atlantic salmon elovl $5 a$ and elovl $5 b$ genes was inconsistent with reports of down-regulation of elovl $5 a^{(25)}$, up-regulation of elovl $5 b^{(22)}$ or no effect on elovl5a or elovl $5 b^{(22,24,25)}$ in response to dietary vegetable oil compared with fish fed fish oil. The Atlantic salmon elovl $5 a$ and elovl $5 b$ may be regulated differently by dietary $n-3$ PUFA or by conditions such as water temperature and fish size, although this is not fully understood. In comparison, juvenile rainbow trout ELOVL5 expression does not seem to be changed significantly in response to different dietary $n$-3 PUFA when reared at water temperatures between 13 and $15^{\circ} \mathrm{C}^{(16)}$.

The present gene regulatory study has shown that FADS2a(A6), ELOVL5 and ELOVL2 are most highly expressed when diets are high in ALA with no added EPA or DHA. Conversely, the expression of all four genes was down-regulated by dietary EPA and DHA, with DHA having the larger and more consistent effect, although ELOVL5 expression was the least responsive to dietary $n-3$ PUFA changes. These findings should be considered when optimising diets containing vegetable oils and/or fish oil or fishmeal to achieve maximum DHA synthesis. A study using larger fish and a longer feeding period is warranted to determine the impact on the percentage of DHA in the edible muscle portion of rainbow trout.

\section{Acknowledgements}

The authors are grateful to Cindy Hall (Rheumatology Unit, Royal Adelaide Hospital, Australia), Karen Hermon, Fernando Norambuena, James Emery, Michael Lewis and Amber Chen (School of Life and Environmental Sciences, Deakin University, Australia) for their assistance during the tissue collection. The authors also thank Karen Hermon for her assistance with the proximate analysis.

This research received no specific grant from any funding agency, commercial or not-for-profit sectors.

M. K. G., D. R. T, M. J. J. and G. M. T. designed the research; M. K. G., R. O. C. and G. M. T. conducted the research; G. M. T. and M. J. J. provided the essential materials; M. K. G. and M. J. J. analysed the data; and M. K. G., D. R. T. and M. J. J. wrote the paper. All authors read and approved the final version of the manuscript.

The authors have no conflicts of interest to declare.

\section{References}

1. Harris WS (2009) The omega-3 index: from biomarker to risk marker to risk factor. Curr Atheroscler Rep 11, 411-417.

2. Turchini GM, Nichols PD, Barrow C, et al. (2012) Jumping on the omega-3 bandwagon: distinguishing the role of long-chain and short-chain omega-3 fatty acids. Crit Rev Food Sci Nutr 52, 795-803.

3. Chen YC, Nguyen J, Semmens K, et al. (2006) Enhancement of omega-3 fatty acid content in rainbow trout (Oncorbynchus mykiss) fillets. J Food Sci 71, C383-C389.

4. Cleveland BJ, Francis DS \& Turchini GM (2012) Echium oil provides no benefit over linseed oil for $(n-3)$ long-chain PUFA biosynthesis in rainbow trout. J Nutr 142, 1449-1455.

5. Hixson SM, Parrish CC \& Anderson DM (2014) Changes in tissue lipid and fatty acid composition of farmed rainbow trout in response to dietary camelina oil as a replacement of fish oil. Lipids 49, 97-111.

6. Masiha A, Mahboobi Soofiani N, Ebrahimi E, et al. (2013) Effect of dietary flaxseed oil level on the growth performance and fatty acid composition of fingerlings of rainbow trout, Oncorbynchus mykiss. Springerplus $\mathbf{2}, 1$.

7. Buzzi M, Henderson RJ \& Sargent JR (1996) The desaturation and elongation of linolenic acid and eicosapentaenoic acid by hepatocytes and liver microsomes from rainbow trout (Oncorbynchus mykiss) fed diets containing fish oil or olive oil. Biochim Biophys Acta 1299, 235-244.

8. Gregory MK \& James MJ (2014) Rainbow trout (Oncorbynchus mykiss) Elovl5 and Elovl2 differ in selectivity for elongation of omega-3 docosapentaenoic acid. Biochim Biophys Acta 1841, 1656-1660.

9. Abdul Hamid NK, Carmona-Antoñanzas G, Monroig Ó, et al. (2016) Isolation and functional characterisation of a fads 2 in rainbow trout (Oncorbynchus mykiss) with $\Delta 5$ desaturase activity. PLOS ONE 11, e0150770.

10. Meyer A, Kirsch H, Domergue F, et al. (2004) Novel fatty acid elongases and their use for the reconstitution of docosahexaenoic acid biosynthesis. J Lipid Res 45, 1899-1909.

11. Zheng X, Seiliez I, Hastings N, et al. (2004) Characterization and comparison of fatty acyl $\Delta 6$ desaturase cDNAs from freshwater and marine teleost fish species. Comp Biochem Physiol B Biochem Mol Biol 139, 269-279.

12. Association of Official Analytical Chemists (2006) Official Methods of Analysis of the Association of Official Analytical Chemists International, 18th ed. Gaithersburg, MD: AOAC International.

13. Folch J, Lees M \& Sloane Stanley GH (1957) A simple method for the isolation and purification of total lipides from animal tissues. J Biol Chem 226, 497-509.

14. Gregory MK, See VH, Gibson RA, et al. (2010) Cloning and functional characterisation of a fatty acyl elongase from southern bluefin tuna (Thunnus maccoyii). Comp Biochem Physiol B Biochem Mol Biol 155, 178-185.

15. Panserat S, Hortopan GA, Plagnes-Juan E, et al. (2009) Differential gene expression after total replacement of dietary fish meal and fish oil by plant products in rainbow trout (Oncorbynchus mykiss) liver. Aquaculture 294, 123-131.

16. Thanuthong T, Francis DS, Manickam E, et al. (2011) Fish oil replacement in rainbow trout diets and total dietary PUFA content: II) effects on fatty acid metabolism and in vivo fatty acid bioconversion. Aquaculture 322-323, 99-108.

17. Turchini GM \& Francis DS (2009) Fatty acid metabolism (desaturation, elongation and $\beta$-oxidation) in rainbow trout fed fish oil- or linseed oil-based diets. Br J Nutr 102, 69-81.

18. Thomassen MS, Rein D, Berge GM, et al. (2012) High dietary EPA does not inhibit $\Delta 5$ and $\Delta 6$ desaturases in Atlantic salmon 
(Salmo salar L.) fed rapeseed oil diets. Aquaculture 360-361, 78-85.

19. Zheng X, Tocher DR, Dickson CA, et al. (2005) Highly unsaturated fatty acid synthesis in vertebrates: new insights with the cloning and characterization of a $\Delta 6$ desaturase of Atlantic salmon. Lipids 40, 13-24.

20. Monroig O, Zheng X, Morais S, et al. (2010) Multiple genes for functional $\Delta 6$ fatty acyl desaturases (Fad) in Atlantic salmon (Salmo salar L.): gene and cDNA characterization, functional expression, tissue distribution and nutritional regulation. Biochim Biophys Acta 1801, 1072-1081.

21. Hastings N, Agaba MK, Tocher DR, et al. (2005) Molecular cloning and functional characterization of fatty acyl desaturase and elongase cDNAs involved in the production of eicosapentaenoic and docosahexaenoic acids from $\alpha$-linolenic acid in Atlantic Salmon (Salmo salar). Mar Biotechnol (NY) 6, 463-474.

22. Morais S, Monroig O, Zheng X, et al. (2009) Highly unsaturated fatty acid synthesis in Atlantic salmon: characterization of ELOVL5- and ELOVL2-like elongases. Mar Biotechnol (NY) 11, 627-639.
23. Jordal AE, Torstensen BE, Tsoi S, et al. (2005) ) Dietary rapeseed oil affects the expression of genes involved in hepatic lipid metabolism in Atlantic salmon (Salmo salar L.). J Nutr 135, 2355-2361.

24. Morais S, Pratoomyot J, Taggart JB, et al. (2011) Genotypespecific responses in Atlantic salmon (Salmo salar) subject to dietary fish oil replacement by vegetable oil: a liver transcriptomic analysis. BMC Genomics 12, 255.

25. Xue X, Hixson SM, Hori TS, et al. (2015) Atlantic salmon (Salmo salar) liver transcriptome response to diets containing Camelina sativa products. Comp Biochem Physiol D Genomics Proteomics 14, 1-15.

26. Zheng X, Tocher DR, Dickson CA, et al. (2004) Effects of diets containing vegetable oil on expression of genes involved in highly unsaturated fatty acid biosynthesis in liver of Atlantic salmon (Salmo salar). Aquaculture 236, 467-483.

27. Zheng X, Torstensen BE, Tocher DR, et al. (2005) Environmental and dietary influences on highly unsaturated fatty acid biosynthesis and expression of fatty acyl desaturase and elongase genes in liver of Atlantic salmon (Salmo salar). Biochim Biophys Acta 1734, 13-24. 